\title{
STRUTHERS' LIGAMENT AND SUPRACONDYLAR HUMERAL PROCESS: AN ANATOMICAL STUDY AND CLINICAL IMPLICATIONS
}

\section{LIGAMENTO DE STRUTHERS E PROCESSO SUPRACONDILAR DO ÚMERO: ESTUDO ANATÔMICO E IMPLICAÇÕES CLÍNICAS}

\author{
Edie Benedito Caetano ${ }^{1}$, João José Sabongi Neto ${ }^{2}$, luiz Angelo Vieira ${ }^{1}$, Maurício Ferreira Caetano $^{2}$, José Eduardo de Bona ${ }^{1}$, \\ ThaIs MAYOR SimonatTo ${ }^{1}$
}

1. Pontifícia Universidade Católica de São Paulo, Faculdade de Ciências Médicas e da Saúde, Sorocaba, SP, Brazil.

2. Conjunto Hospitalar de Sorocaba, Department of Hand Surgery, Sorocaba, SP, Brazil.

\begin{abstract}
Objective: The objective of this study was to determine the frequency and anatomical characteristics of Struthers' ligament and the supracondylar humeral process and evaluate the clinical implications in compressive neuropathy of the median nerve. Method: We dissected 60 arms from 30 cadavers (26 males and 4 females): 15 were previously preserved in formalin and glycerin and 15 were dissected fresh in the Anatomy Laboratory for this paper. The relationships between Struthers' ligament and the median nerve and brachial artery and veins were documented with drawings and photos. Results: The supracondylar humeral process was not found in any of the 60 dissected arms. Struthers' ligament was identified in six arms (two bilateral); in all cases high insertion of the pronator teres muscle was observed. Conclusion: Struthers' ligament is an aponeurotic structure that may or may not be associated with the supracondylar humeral process, and is an important potential site of median nerve compression in the lower third of the arm. Level of Evidence IV, Case Series.
\end{abstract}

Keywords: Ligaments. Nerve compression syndromes. Median nerve. Humerus.

\section{RESUMO}

Objetivo: Determinar a frequência e as características anatômicas do ligamento de Struthers e do processo supracondilar do úmero e avaliar sua implicação clínica na neuropatia compressiva do nervo mediano. Método: Foram dissecados 60 membros superiores de 30 cadáveres de adultos, 26 do sexo masculino e quatro do sexo feminino, 15 previamente preservados em formol e glicerina e 15 dissecados a fresco no Laboratório de Anatomia. A relação do ligamento de Struthers com o nervo mediano e a artéria e veias braquiais, foi documentada com desenhos e fotografias. Resultados: O processo supracondilar do úmero não foi encontrado em nenhum dos 60 braços dissecados. O ligamento de Struthers foi identificado em seis membros (dois bilaterais); em todos havia inserção alta do músculo pronador redondo. Conclusão: O ligamento de Struthers é uma estrutura aponeurótica que pode estar ou não associada ao processo supracondilar do úmero e representa local de possível compressão do nervo mediano no terço inferior do braço. Nível de Evidência IV, Série de Casos.

Descritores: Ligamentos. Síndromes de compressão nervosa. Nervo mediano. Úmero.

Citation: Caetano EB, Sabongi Neto JJ, Vieira LA, Caetano MF, Bona JE, Simonatto TM. Struthers' ligament and supracondylar humeral process: an anatomical study and clinical implications. Acta Ortop Bras. [online]. 2017;25(4):137-42. Available from URL: http://www.scielo.br/aob.

\section{INTRODUCTION}

Struthers' ligament was described by the anatomist John Struthers ${ }^{1}$ in 1848; this fibrous band extends from a bone spike located on the anteromedial face of the lower third of the humerus known as the supracondylar process and is part of the medial epicondyle of the humerus. Struthers' ligament passes over the median nerve and the brachial artery, and can cause compression of these structures. This ligament may be present even when the supracondylar process is absent, and even when it is present may not cause the compression of these structures. The supracondylar process of the humerus has been described by anatomists and anthropologists and is phylogenetically considered to be a remnant of the supracondylar foramen found in reptiles, marsupials, and some mammals. ${ }^{2,3}$ Kessel and Rang 4 consider that from the embryonic point of view, Struthers' ligament is a remaining vestige of the tendon of the latissimus-condyloid muscle tendon, which is found in some climbing animals and serves as an anchor for the pronator teres muscle. In the lower mammals, the tunnel of osteo-fibrous tissue formed by the humerus, the supracondylar process and Struthers' ligament protects the nerves and blood vessels that extend to the forearm. ${ }^{4}$ Its occurrence in humans is very rare, in only $0.7-2.5 \%$ of the population. ${ }^{4-6}$ It is more frequent in women and Europeans and

All authors declare no potential conflict of interest related to this article.

Work conducted at the Pontifícia Universidade Católica de São Paulo, Faculdade de Ciências Médicas e da Saúde, Sorocaba, SP, Brazil. 
is extremely rare in Black individuals. ${ }^{7}$ Some authors have reported familial occurrence of this bone spike. 5,6

Struthers' ligament and the arcade of Struthers are two different anatomical structures which are often confused. The arcade of Struthers was first described in 1973 by Kane et al. ${ }^{8}$ and has sometimes been defined as a thickening of the brachial fascia, and at other times as an aponeurotic or musculoaponeurotic structure which extends from the medial intermuscular septum to the medial head of the triceps brachii muscle at a variable distance above the medial epicondyle of the humerus. The arcade of Struthers can cause compression of the ulnar nerve.

Compression of the median nerve in the elbow is usually caused by the presence of fibrous bands, which may be seen in four different anatomic locations in the following order of frequency: ${ }^{9}$ between the superficial and deep heads of the pronator teres muscle, in the arcade formed by the proximal insertions of the superficial flexor muscle, in the bicipital aponeurosis (lacertus fibrosus), and in Struthers' ligament which may or may not be associated with the supracondylar process of the humerus. Clinically, it is not easy to identify the exact location of compression. The most common cause of median nerve compression syndrome in this region occurs between the humeral and ulnar heads of the pronator teres muscle. However, the decreased muscle strength of the pronator teres suggests compression above the elbow. Some provocative tests can be used to differentiate the location of the nerve compression:9,10 1. Pronation of the forearm against resistance with the elbow flexed and then gradually extended indicates compression between the two heads of the pronator teres muscle. To test the pronator teres muscle alone, the elbow must be extended and supported on a flat surface, with the patient prone and the forearm against resistance with the arm in neutral rotation and the wrist flexed (to relax the superficial muscular flexor of the fingers). Pain and paresthesia show the involvement of the pronator teres muscle in compression of the median nerve. 2. Independent flexion of the middle finger against resistance reproduces the paresthetic symptoms in the area where the median nerve innervates indicates compression in the arch formed between the proximal insertions of the superficial flexor muscle. 3. Elbow flexion and supination of the forearm against resistance reproduces the symptoms and indicates compression by the bicipital aponeurosis (lacertus fibrosus). 4. Compression by Struthers' ligament is usually associated with pain in the forearm that is accentuated during extension of the wrist. The elbow is flexed against resistance and simultaneously palpating the area 5 to $10 \mathrm{~cm}$ above the medial epicondyle in an attempt to palpate the supracondylar process of the humerus. Radiological examination rules out the presence of the supracondylar process. Tinel's sign can be useful to find the location of the compression. The results of electrophysiological examinations are consistent with a nerve compression at the elbow, suggesting but not confirming the exact location of the compression. ${ }^{9}$ Only surgical exploration of the nerve can identify the structure responsible for nerve compression. 9,10 The objective of this study was to analyze 60 limbs from 30 cadavers in order to identify the presence of Struthers' ligament and the supracondylar process of the humerus, along with the possibility that these anatomical variations may be responsible for compression of the median nerve.

\section{MATERIALS AND METHODS}

We dissected 60 forearms of 30 adult cadavers belonging to the Anatomy Department Laboratory to conduct this study; 26 corpses were male and four were female, 15 had previously been preserved in formaldehyde and glycerin and 15 were fresh cadavers. Ages ranged from 28 to 77 years, 17 were white and 13 were non-white. Forearms deformed by trauma, congenital malformations, and scars were excluded. The dissection was performed through a midline incision in the arm and forearm, and two flaps including the skin and subcutaneous tissue were folded back to the radial and ulnar sides, respectively. This same process was repeated for the fascia of the arm and forearm, exposing all the musculature. The median nerve was identified in the proximal third of the arm in the medial margin of the brachial biceps muscle and dissected distally, analyzing the presence of any fibrous bands, Struthers' ligament, and the supracondylar process of the humerus that could narrow its passage. The dissection continued distally on the forearm where we analyzed the presence of nerve compression from the bicipital aponeurosis, between the humeral and ulnar heads of the pronator teres muscle and through the archway formed between the radial and ulnar humerus inserts of the superficial flexor muscle, and also identified the Gantzer muscle, the Martin-Gruber anastomosis, and possible anatomical variations. These are part of studies that have already been published or are forthcoming. The anatomical variations were identified, recorded, and photographed. We used a Keeler 2.5x magnifying glass. The study was approved by the institutional review board under process number 1,611,295.

\section{RESULTS}

In all 60 dissected arms we recorded that in the middle third of the arm, the median nerve crossed in front of the brachial artery in a lateral-to-medial direction and proceeded toward the cubital fossa, where it was positioned medially to the brachial artery and the tendon of the biceps brachii muscle. The supracondylar process of the humerus was not found in any of the 60 dissected arms. Struthers' ligament was identified in 6 arms (two bilateral) and in all cases the pronator teres muscle had a high insertion. In the right arm of one cadaver we identified high insertion of the pronator teres muscle where it came from a cord-shaped ligament positioned on the median nerve and brachial artery, inserting into the diaphysis of the humerus. (Figure 1A) On the left side the ligament originated from the same place and was inserted proximally, but had no relation with the median nerve and brachial artery. (Figure 1B) Unlike Struthers' ligament, the arcade of Struthers is an aponeurotic or musculoaponeurotic structure which extends from the medial intermuscular septum to the medial head of the triceps brachii muscle. (Figure 2A) A case similar to the situation in Figure 1B was recorded in the left arm of another cadaver. (Figure 2B) In two arms from one cadaver, we identified an anatomical variation consisting of high insertion of the humeral head of the pronator teres muscle which was inserted through a short ligament in the diaphysis of the humerus causing pressure on the median nerve and brachial artery, but there was no bone spike. (Figures $3 \mathrm{~A}$ and 3B) We identified two similar cases on the right arm of a recently-deceased cadaver and in the left arm of another cadaver preserved in formaldehyde and glycerin; Struthers' ligament was composed of a fibrous lamina originating in the medial epicondyle and adjacent brachial fascia, moving upwards and passing over the median nerve and brachial artery to insert itself into the fascia of the brachial muscle and the humeral shaft. (Figures 4A and 4B)

\section{DISCUSSION}

Nerve compression in the elbow region is generally called pronator teres syndrome because compression most frequently occurs between the two heads of this muscle. ${ }^{9}$ Tubbs et al. ${ }^{11}$ considered this nomenclature to be incorrect when compression occurs 

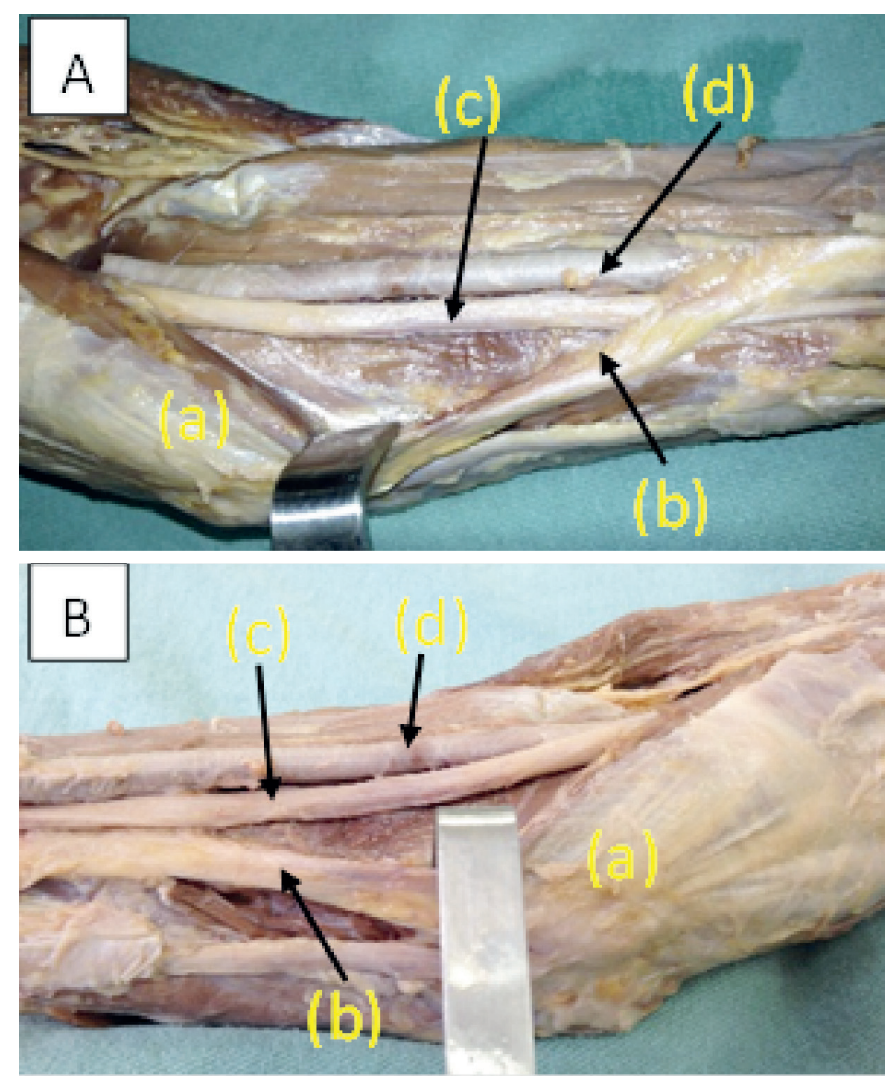

Figure 1. A) In the right arm of one corpse, we identified high insertion of the pronator teres muscle (a) from which a cord-shaped ligament originated (b) and was positioned on the median nerve (c) and the brachial artery (d) inserting into the diaphysis of the humerus. B) On the left side, the ligament originated in the same place and was inserted proximally but had no relation to the median nerve or brachial artery. The pronator teres muscle (a); Struthers' ligament (b); median nerve (c); brachial artery (d)

through Struthers' ligament, bicipital aponeurosis, or through the archway of the superficial flexor, and suggested that the correct name would be compressive neuropathies proximal to the median nerve and not pronator teres syndrome. Struthers' ligament and supracondylar process of the humerus can be asymptomatic and differ from the osteocartilagenous exostosis because they do not have a cartilaginous cap and histologically are normal bone in continuity with the humeral cortex. ${ }^{6}$ The cartilaginous cap can be visualized using magnetic resonance imaging. ${ }^{6,12}$ Clinical abnormalities caused by the supracondylar process of the humerus were first described by Soliere, ${ }^{13}$ who described sensory and motor changes in the median nerve which was compressed by the supracondylar process of the humerus in a 19 -year-old man. Suranyi ${ }^{14}$ reported the case of a 60-year-old patient exhibiting progressive weakness, pain, and numbness in the left forearm and hand. Clinical examination showed that these changes occurred in the area of distribution of the median nerve. Electrophysiological examination showed impairment of the nerve in the segment immediately proximal to the elbow. Surgery revealed that Struthers' ligament was the cause of the compression of the median nerve. The bone spike was not found via palpation or x-ray examination. Sectioning of the Struthers' ligament relieved the symptoms. Caetano and Brandi ${ }^{15}$ reported the case of a 26 -year-old patient with pain in the shoulder, forearm, and hand as well as numbness of the hand for six months; he was unable to fully extend his left or right elbows. During palpation the presence of a hard and painful tumor was noted on the antero-medial surface
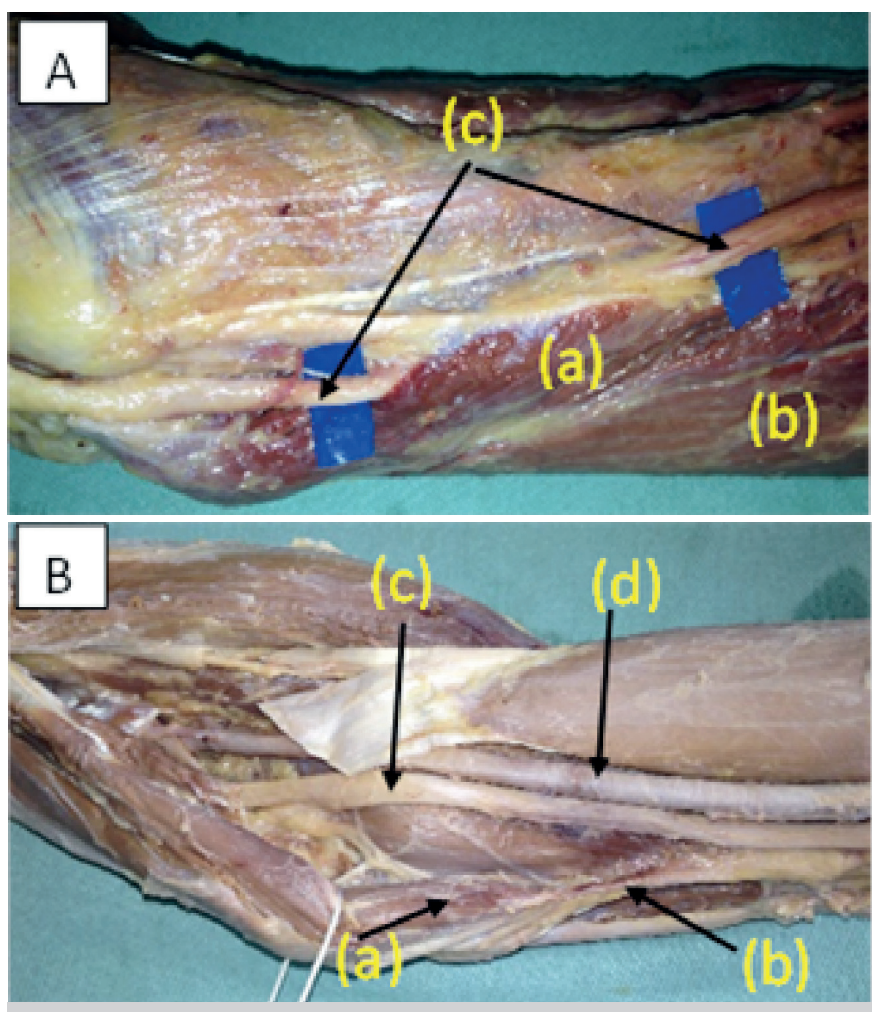

Figure 2. A) The arcade of Struthers (a) is a musculoaponeurotic structure which extends from the medial intermuscular septum to the medial head of the triceps brachii muscle (b). It is positioned anterior to the ulnar nerve (c) and may compress this structure. B) A case similar to the situation in Figure $1 \mathrm{~B}$ was recorded in the left arm of another cadaver. Pronator teres muscle (a). Struthers' ligament (b). Median nerve (c). Brachial artery (d).

of the lower third of the left and right arms; it was more extensive on the right side with positive Tinel's sign at the level of the tumor. On this side there was a limitation of 35 degrees extension and 30 degrees supination. Pain was exacerbated with passive supination and active pronation with simultaneous extension of the elbow. There were no signs of vascular compression. The left arm had a limitation of 15 degrees of extension and 20 of supination, and negative Tinel's sign with no symptoms of neurovascular compression. Radiological examination showed the presence of a 3-cm bone spike in the right arm and a $1.5-\mathrm{cm}$ bone spike in the left arm. Surgery showed that the pronator teres muscle was inserted abnormally via a short ligament in the supracondylar process of the humerus. (Figure 5A) Disinsertion of the muscle and resection of the bone spike resulted in decompression of the median nerve. (Figure 5B) Clinical improvement was already evident in the second month after surgery. After 18 months, the patient was completely asymptomatic. The pronator teres muscle was reinserted in the medial epicondyle of the humerus. In our dissections we identified in both arms from a single cadaver an anatomical variation identical to that registered in the clinical case described above. The pronator teres muscle was inserted the same way via a short ligament in the diaphysis of the humerus, but there was no bone spike. (Figures 4A and B) We do not know the medical history of this individual, but the narrowing of the space where the nerve passed was evident. Aydinlioglu et al. ${ }^{16}$ described the rare case of a 21-year-old woman who complained of pain, sensory disturbances, and loss of motor function in the area where the median nerve innervated in both arms. Clinical examination identified the presence of a painful bone spur in the distal third of the humerus. Radiological and electrophysiological 

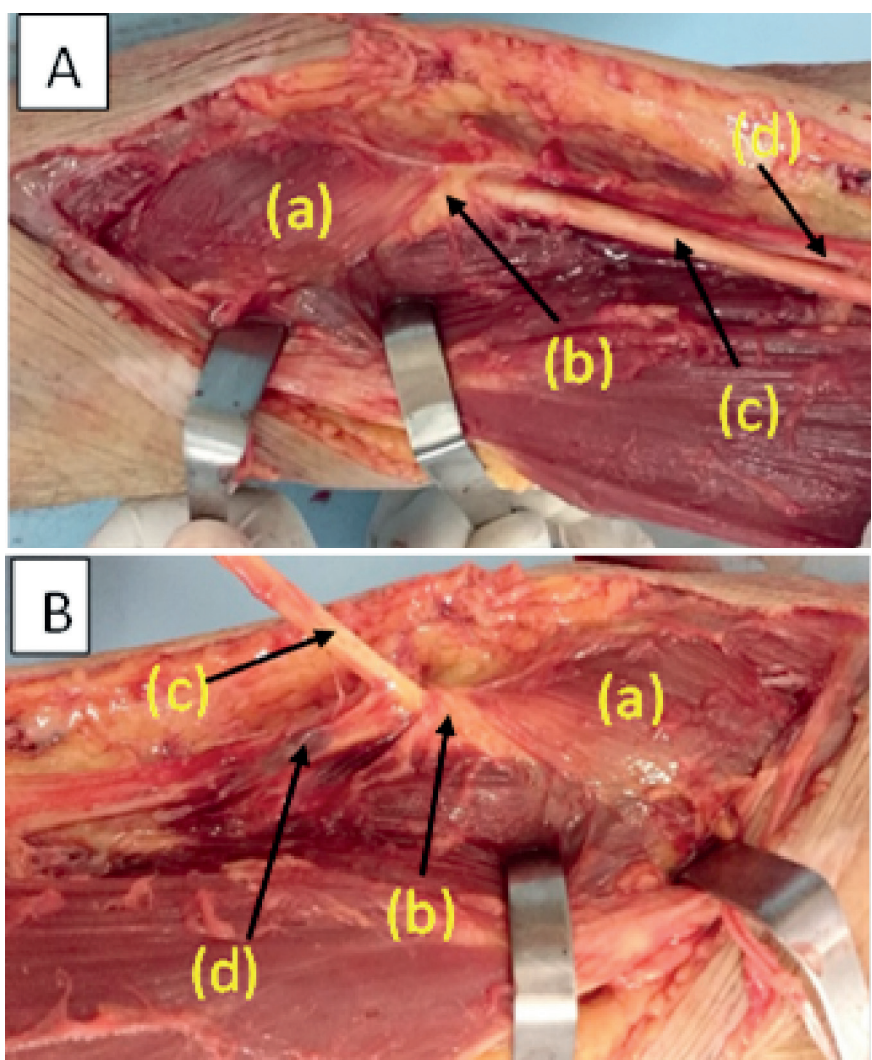

Figure 3. A-B) In one cadaver, we identified a bilateral anatomical variation consisting of high insertion of the humeral head of the pronator teres muscle (a) which was inserted through a short ligament (b) in the diaphysis of the humerus causing pressure on the median nerve (c) and brachial artery (d), but no bone spike was seen.

examination confirmed the diagnosis of bilateral compression of the median nerve caused by Struthers' ligament. These authors stated that this was the first reported case of bilateral compression of the median nerve caused by this ligament. The patient underwent surgical decompression of the nerve on both sides and symptoms were relieved after two weeks. These authors described the importance of removing the adjacent periosteum to avoid regrowth in the supracondylar process. Lordan et al. ${ }^{17}$ reported the case of a 13-year-old boy with a history of 4 weeks of vague pain in the left forearm after hitting his elbow during sports activity. Palpation identified a hard mass along the distal humerus. X-ray revealed a bone spike $5 \mathrm{~cm}$ proximal to the elbow. The clinical history showed the boy had paresthesia in the ipsilateral thumb, index finger, middle and radial half of the ring finger, as well as pain in the forearm during pronossupination. Physical examination revealed mild weakness in grip strength, but no atrophy of the thenar muscles or sensory deficits of the hand. Because the neurological symptoms were persistent, the patient underwent surgery. Struthers' ligament and supracondylar process were identified as responsible for the symptoms. The ligament was sectioned and the supracondylar process removed, and the symptoms consequently disappeared. These authors also stated that compression of the median nerve by Struthers' ligament and the supracondylar process should be considered in cases where symptoms persist after decompression of the median nerve in the carpal tunnel. Petret et al. ${ }^{18}$ presented the case of a professional tennis player with a stress fracture in the supracondylar process of the humerus who underwent surgery to avoid possible displacements and neurovascular
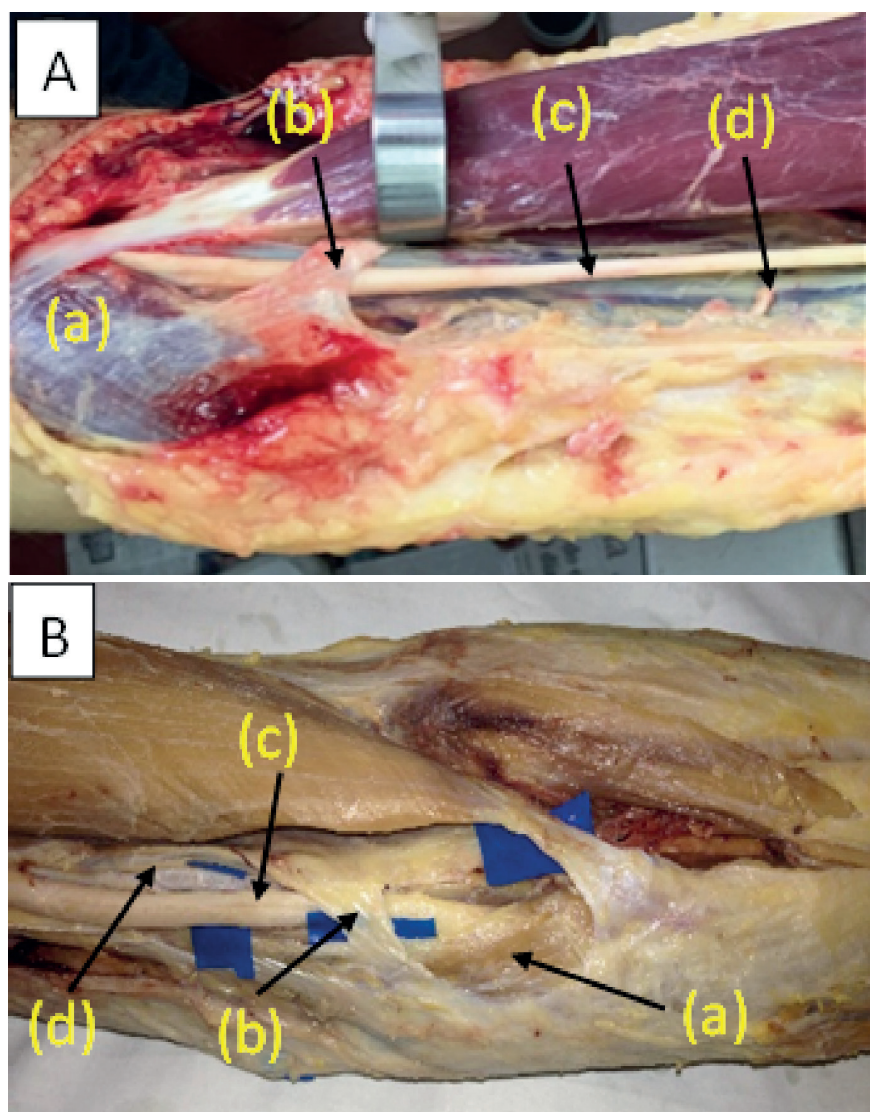

Figure 4. We identified two similar cases $(A)$ in the right arm of a recently-deceased cadaver and (B) in the left arm of another cadaver preserved in formaldehyde and glycerin; the Struthers' ligament was composed of a fibrous lamina (b) originating in the medial epicondyle and adjacent brachial fascia, moving upwards and passing over the median nerve (c) and brachial artery (d) to insert itself into the fascia of the brachial muscle and the humeral shaft. Pronator teres (a).

complications. These authors state that this was the first report of a stress fracture in the supracondylar process, and believed that the excessive traction of the pronator teres caused the fracture, which was seen in both X-ray and MR imaging. Jelev et al. ${ }^{19}$ reported noticing an unusually high insertion for the pronator teres muscle during routine anatomic dissection of the right arm of a 53-year-old female cadaver; this insertion had two bone origins, one in the medial epicondyle and a smaller insertion in the supracondylar process of the humerus, with tendinous arch (Struthers' ligament) extending between them with the median nerve and brachial vessels passing through this arch. They noticed that the musculocutaneous nerve was absent and that the coracobrachialis, brachialis, and biceps brachialis muscles received innervation from the median nerve.

The anatomical relationships between the supracondylar spur and Struthers' ligament and the neighboring neurovascular structures have been clearly demonstrated in MR imaging by some authors. ${ }^{20,21}$ Other associated anatomical variations may occur: high insertion of the pronator teres, high division of the brachial artery, low insertion of the coracobrachialis muscle, or high origin of the anterior interosseous nerve. ${ }^{22}$ In the left arm of a cadaver with a high origin for the pronator teres muscle, we noted low insertion of the coracobrachialis muscle and high origin of the anterior interosseous nerve, (Figure 6A) but did not identify Struthers' ligament, the supracondylar process, 

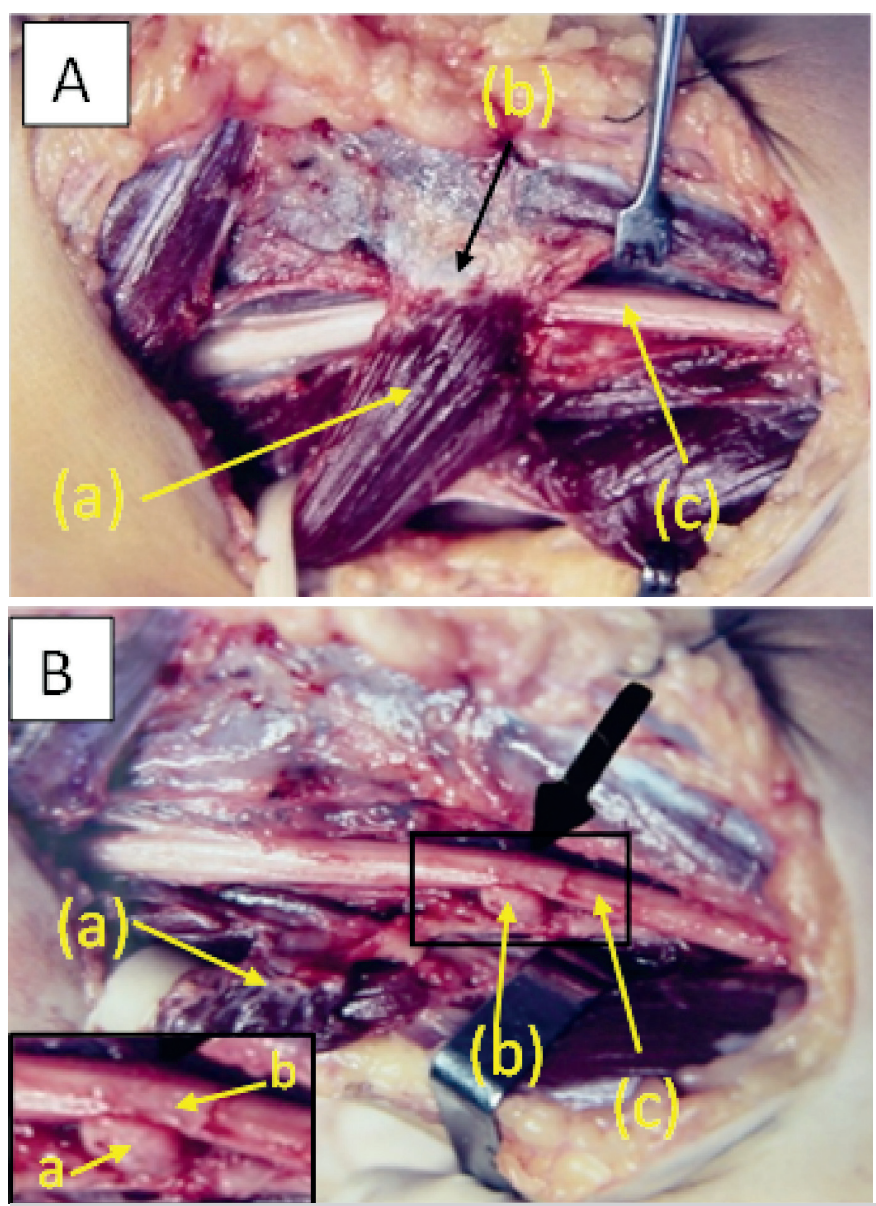

Figure 5. A) Clinical case. In one cadaver, we identified a bilateral anatomical variation consisting of high insertion of the humeral head of the pronator teres muscle (a) which inserted via a short ligament (b) in the supracondylar process of the humerus, compressing the median nerve (c). B) Surgery showing the pronator teres muscle disinserted (a) from the supracondylar process of the humerus (b) and compressing the median nerve (c). Detail: supracondylar process (a) and median nerve (b)

or high division of the brachial artery in this cadaver. The proximity of the ligament and the supracondylar process to the brachial artery and veins can cause symptoms resulting from the compression of these structures, with ischemic episodes of pain and changes in the arterial pulses which have been previously described. ${ }^{4,6}$ Some authors ${ }^{4,23}$ have indicated that Struthers' ligament can compress the ulnar nevus, but consider this phenomenon to be very rare. We did identify a case not belonging to this series (but rather in a demonstration of access routes to the elbow) in which Struthers ligament originated in the medial epicondyle and moved proximally, fanning out and inserting into the brachial fascia and the internal brachial ligament and passing over the ulnar nerve in precisely the place where the nerve passed from the anterior compartment to the posterior of the arm. (Figure 6B) Gessini et al. ${ }^{24}$ considered compression of the median nerve by Struthers' ligament to be very rare, and reported that in a series of 228 patients with compressive syndromes of the median nerve, only three cases occurred above
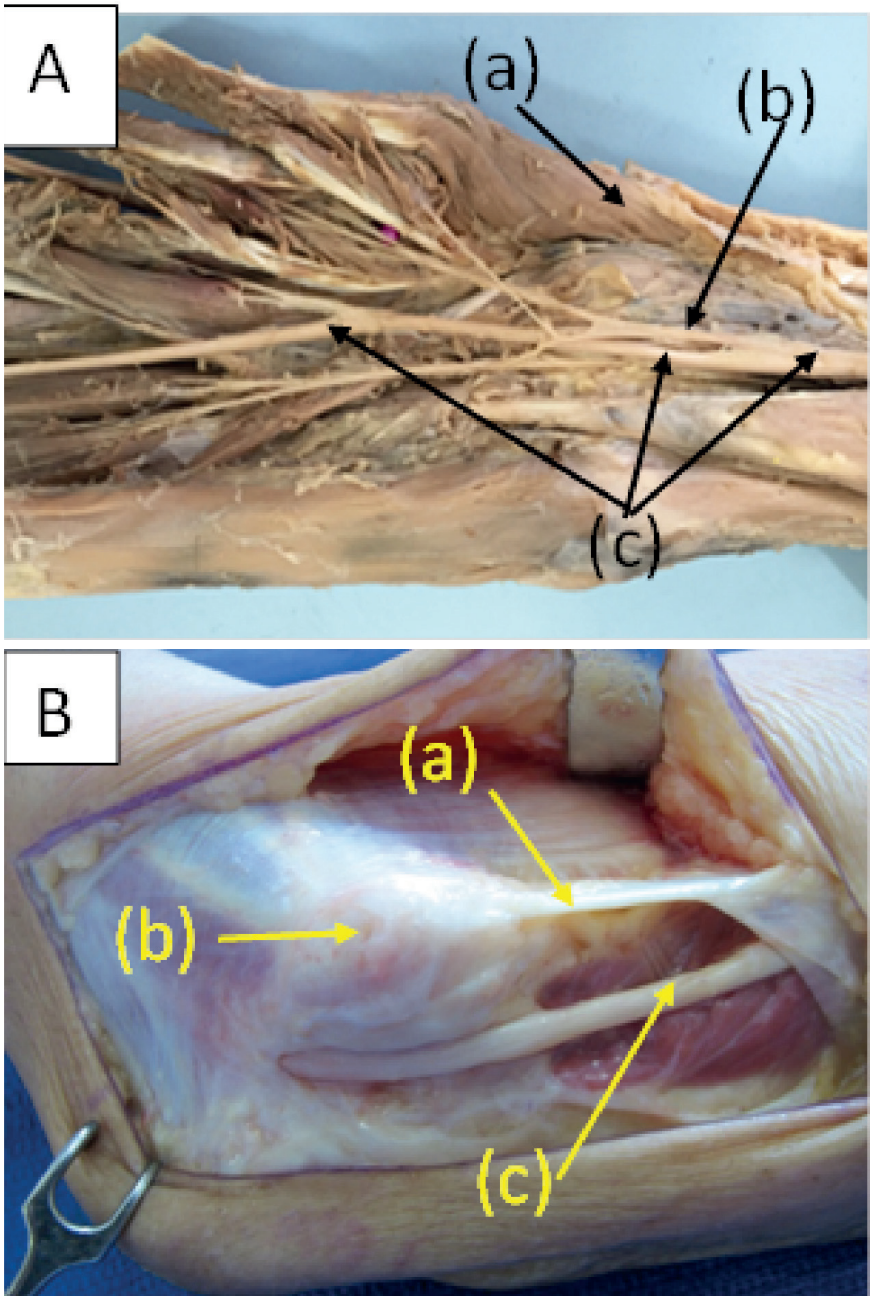

Figure 6. A) High insertion of the pronator teres muscle (a) associated with high origin of the anterior interosseous nerve (above the elbow joint) (b). Median nerve (c). B) The Struthers' ligament (a) originated in the medial epicondyle (b) and moved proximally, fanning out and inserting into the brachial fascia and the internal brachial ligament and passing over the ulnar nerve (c) in precisely the place where the nerve passed from the anterior compartment to the posterior of the arm.

the elbow: one case involving Struthers' ligament and two involving the bicipital aponeurosis, 201 cases of carpal tunnel syndrome, 21 cases involving the pronator teres muscle, and three involving the anterior interosseous nerve.

\section{CONCLUSION}

Struthers' ligament is a rare aponeurotic structure that may or may not be associated with the supracondylar process of the humerus and may compress the median nerve against the deeper structures, changing the normal course of the nerve; it is consequently one of the rare potential sites for nerve compression which narrow the space where nerves pass and consequently can cause motor and sensory symptoms.

AUTHORS' CONTRIBUTIONS: Each author made significant individual contributions to this manuscript. EBC (0000-0003-4572-3854)*, LAV (0000-00034406-2492) * and MBFC (0000-0003-0994-2128)* were the main contributors in drafting the manuscript. JEB (0000-0002-2416-7281)* and TMS (0000-00020654-5373)* conducted the bibliographical research. All authors participated in dissecting and photographing the cadavers. EBC and JJSN (0000-00020554-1426)* reviewed the manuscript, contributed to the intellectual concept, coordinated the study, and were responsible for directing the other participants. *ORCID (Open Researcher and Contributor ID). 


\section{REFERENCES}

1. Struthers J. On a peculiarity of the humerus and humeral artery. Mon J Med Sci. 1848;28:264-7

2. Dwight T. A bony supracondyloid foramen in man. Am J Anat. 1904;3:221.

3. Kolb LW, Moore RD. Fracture of the supracondyloid process of the humerus. J Bone Joint Surg Am. 1967;49:532-8.

4. Kessel L, Rang M. Supracondilar spur of the humerus. J Bone Joint Surg Br. 1966;48(4):765-8.

5. Barnard LB, McCoy SM. The supra condyloid process of the humerus. J Bone Joint Surg Am. 1946;28(4):845-50.

6. Engber WD, McBeath AA, Cowle AE. The supracondylar process. Clin Orthop Relat Res. 1974;(104):228-31.

7. Terry RJ. On the racial distribution of the supracondyloid variation. Am J Phys Anthropol. 1930;14:459-62.

8. Kane E, Kaplan EB, Spinner M. Observations of the course of the ulnar nerve in the arm. Ann Chir. 1973;27(5):487-96.

9. Spinner M. Injuries to the major branches of the peripheral nerves of the forearm. Philadelphia: WB Saunders; 1978. p. 160-227.

10. Rengachary SS. Entrapment neuropathies. In: Wilkins $\mathrm{RH}$, Rengachary SS, editors. Neurosurgery. New York: McGraw- Hill; 1985. p. 1771-95.

11. Tubbs RS, Marshall T, Loukas M, Shoja MM, Cohen-Gadol AA. The sublime bridge: anatomy and implications in median nerve entrapment. J Neurosurg. 2010;113(1):1102.

12. Meschan I. Roentgen signs in diagnostic imaging. 2nd ed. Philadelphia: WB Saunders; 1985.

13. Soliere SB. Nevralgia del nervo mediano da processo supra epitrocleare. Chir Organi Mov. 1929;14:171-80.
14. Suranyi L. Median nerve compression by Struthers ligament. J Neurol Neurosurg Psychiatry. 1983;46(11):1047-9.

15. Caetano EB, Brandi S. Compressão do nervo mediano por processo supracondilar do úmero. Rev Bras Ortop. 1989;24(9):323-6.

16. Aydinlioglu A, Cirak B, Akpinar F, Tosun N, Dogan A. Bilateral median nervecompression at the level of Struthers' ligament. Case report. J Neurosurg. 2000;92(4):693-6.

17. Lordan J, Rauh P, Spinner RJ. The clinical anatomy of the supracondylar spur and the ligament of Struthers. Clin Anat. 2005;18(7):548-51.

18. Pedret C, Balius R, Alomar X, Vilaró J, Ruiz-Cotorro A, Minoves M. Stress fracture of the supracondylar process of the humerus in a professional tennisplayer Clin J Sport Med. 2015;25(1):e20-2.

19. Jelev L, Georgiev GP. Unusual high-origin of the pronator teres muscle from a Struthers' ligament coexisting with a variation of the musculocutaneous nerve. Rom J Morphol Embryol. 2009;50(3):497-9.

20. Ay S, Bektas U, Yilmaz C, Diren B. An unusual supracondylar process syndrome J Hand Surg Am. 2002;27(5):913-5.

21. Newman A. The supracondylar process and its fracture. Am J Roentgenol Radium Ther Nucl Med. 1969;105(4):844-9.

22. Gunther SF, DiPasquale D, Martin R. Struthers' ligament and associated median nerve variations in a cadaveric specimen. Yale $\mathrm{J}$ Biol Med. 1993;66(3):203-8

23. Casadei R, Ferraro A, Ferruzzi A, Innao V, Mercuri M. Supracondylar process of the humerus: four cases. Chir Organi Mov. 1990;75(3):265-77.

24. Gessini L, Jandolo B, Pietrangeli A. Entrapment neuropathies of the median nerve at and above the elbow. Surg Neurol. 1983;19(2):112-6. 